\title{
Role of transvaginal ultrasound in assessment of endometrial pathology in patients with post-menopausal bleeding
}

\author{
Sudha Menon*, Sreekumari R.
}

Department of Obstetrics and Gynecology, SAT Hospital, Government Medical College, Trivnadrum, Kerala, India

Received: 14 January 2017

Accepted: 27 February 2017

\author{
*Correspondence: \\ Dr. Sudha Menon, \\ E-mail: smprasadam@gmail.com
}

Copyright: () the author(s), publisher and licensee Medip Academy. This is an open-access article distributed under the terms of the Creative Commons Attribution Non-Commercial License, which permits unrestricted non-commercial use, distribution, and reproduction in any medium, provided the original work is properly cited.

\begin{abstract}
Background: Post-menopausal bleeding (PMB) is the most distressing problem in females Endometrial thickness (EMT) as assessed by transvaginal ultrasound (TVS) aids in diagnosing endometrial pathology. This study analyses usefulness of TVS as a diagnostic tool in the evaluation of PMB.

Methods: A prospective study was conducted in 100 patients. Correlation of EMT by TVS was compared with gold standard of histopathological examination (HPE) of the endometrium by fractional curettage (FC).

Results: Mean age was $56.9 \pm 8.03$ years and mean parity status was $2.83 \pm 1.45$. Mean duration after menopause to presentation of bleeding per vaginum was $5.7 \pm 3.85$ years. As per the receiver operating characteristic curve (ROC) analysis, an EMT of $10.8 \mathrm{~mm}$ had a high negative predictive value $(99.1 \%)$ for malignancy with moderate specificity $(62.79 \%)$ and high sensitivity $(92.3 \%)$.

Conclusions: TVS can be easily performed and is less expensive and a useful diagnostic tool in the evaluation of PMB with a cut off value of $10.8 \mathrm{~mm}$ EMT gives a high sensitivity $(92.3 \%)$ and moderate specificity $(62.79 \%)$.
\end{abstract}

Keywords: Carcinoma endometrium, Endometrial thickness, Postmenopausal bleeding, Transvaginal ultrasound

\section{INTRODUCTION}

Menopause is said to have occurred after 12 consecutive months of amenorrhea for which no pathological cause is found. The cessation of follicular function results in negligible amounts of oestrogen which is insufficient to stimulate the endometrium leading to amenorrhea. The average age of menopause is 51 years in western population and 48.3 years in Indian population. ${ }^{1}$ Postmenopausal bleeding (PMB) can be multifactorial. It may be due to endometrial or endocervical polyp, sub mucus myoma, endometrial hyperplasia (adenomatous /atypical), anovulatory endometrium, uterine carcinoma (endometrium or cervix). ${ }^{1-3}$ The most common cause of postmenopausal bleeding is found to be atrophic endometrium and hormone replacement therapy. ${ }^{4}$ The basic pathology in PMB being endometrial hyperplasia induced by oestrogen. Post-menopausal women continue to have measurable levels of estrone and estradiol even though the production of progesterone completely ceases after menopause, thereby providing a hormonal milieu for unopposed stimulation of endometrium by oestrogen. This may lead to the risk of endometrial hyperplasia and carcinoma which commonly presents with PMB. Postmenopausal bleeding needs evaluation urgently as 5$15 \%$ cases are caused by carcinoma endometrium or cervix. $^{5}$

Fractional curettage, an invasive technique was considered as gold standard for evaluation of PMB, but is uncomfortable and associated with anesthetic risk especially in this population with high prevalence of diabetes, hypertension and obesity.$^{6-8}$

Transvaginal ultrasound (TVS) has been established as the first step in the evaluation of PMB.$^{9,10}$ In addition to evaluation of endometrial thickness, TVS also provides information regarding other causes like polyp, myoma 
and adnexial pathology etc. Endometrial thickness of normal atrophic uterus of a postmenopausal woman does not exceed 4- $5 \mathrm{~mm} .{ }^{11-13}$. Endometrial thickness of $<4 \mathrm{~mm}$ correlated with atrophic endometrium in 289 patents with post menopausal bleeding in a study by Guner et al. ${ }^{14}$ $74.8 \%$ of patients had a positive predictive result, $25.2 \%$ had endometrial thickness of $6.1 \pm 3.7 \mathrm{~mm}$ but tissue was insufficient for diagnosis and concluded that a cut off value of $<4 \mathrm{~mm}$ for endometrial thickness had a negative predictive accuracy of $100 \% 14$. Similarly endometrial thickness of $<4 \mathrm{~mm}$ had higher negative predictive value in postmenopausal bleeding in studies by Ciatto et al and Gull et al. ${ }^{15,16}$

A study by Conoscenti et al, trans-vaginal sonography showed sensitivity, specificity, positive predictive and negative predictive value of $55 \%, 96.1 \%, 68.75 \%$ and $93.2 \%$ respectively in detecting pre-malignant and malignant endometrial pathology. ${ }^{13}$ Thus a vast majority of patients with PMB can be managed expectantly with reassurance. The value of an approach to distinguish such patients from those of with organic pathology by a safe, painless and convenient method is obvious. Higher values of EMT indicate endometrial hyperplasia or endometrial carcinoma. $^{16,17}$

This study is aimed at comparing the endometrial thickness as measured by TVS with histopathology of the endometrium in patients with PMB and to define a cut off value of EMT by plotting a Receiver Operating Characteristic curve (ROC) for identifying patients at risk for malignancy.

\section{METHODS}

This is a prospective study with a diagnostic tool evaluation performed in a tertiary care referral centre, Sree Avittam Thirunal Hospital, Trivandrum Kerala, South India. Prospective postmenopausal patients with bleeding per vaginum who attended the hospital for evaluation between June 2014 and December 2014 were recruited for the study.

Inclusion criteria were any patient with PMB with no palpable pathology by thorough clinical examination. The exclusion criteria were as follows.

- Patients unwilling to participate

- Patients with bleeding per vaginum within 1 year of amenorrhea

- Patients on oral anticoagulants/ antithrombotic therapy

- Patients with hematological disorders

- Patients with obvious uterine and adenexal pathology

During the study period a total of 165 patients presented with post-menopausal bleeding of which 109 patients who satisfied the inclusion criteria were included. After detailed history and thorough clinical examination, TVS was done for all patients to assess the endometrial thickness and morphology and exclude uterine and adenexal pathology, Fractional curettage was done for all study patients and curettings were sent for histopathological examination. Histopathology was classified as Proliferative endometrium, Atrophic endometri-um, Secretary endometrium, Simple hyperplasia, Atypical hyperplasia and Carcinoma endomte-rium. ${ }^{18,19}$

Data was analyzed using standard statistical methods. A Receiver operating Characteristic curve (ROC) was plotted to obtain the cut off value of endometrial thickness assessed by TVS. The sensitivity, specificity, positive predictive value, and negative predictive value were assessed.

\section{RESULTS}

A total of 109 patients were included in the analysis. Mean age was 56.9 \pm 8.03 years (age range 46- 84 years) and the mean parity status was $2.83 \pm 1.45$ and mean duration after menopause to PMB was $5.73 \pm 3.85$ years. $22.01 \%$ of patients were hypertensive, $17.43 \%$ were having diabetes mellitus and $58 \%$ were obese.

\section{Histopathology observations}

Majority of the patients had atrophic endometrium $(35.78 \%)$. Simple hyperplasia and atypical hyperplasia were seen in $8.26 \%$ and $10.09 \%$ patients respectively. Carcinoma endometrium was reported in $4.59 \%$ of patients and proliferative endometrium in $27.52 \%$ and secretary endometrium was reported in $4.59 \%$.

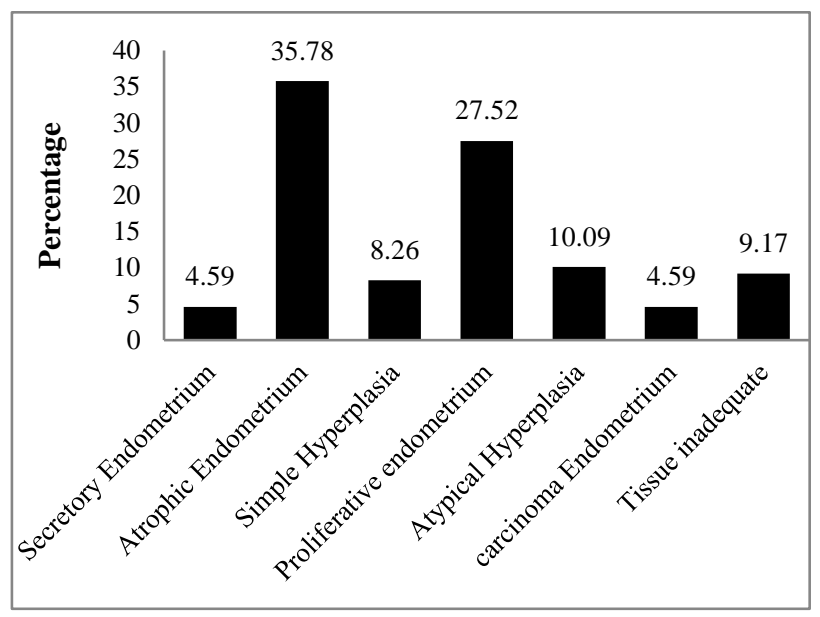

Figure 1: Distribution of histopathological changes in the endometrium.

Highest mean endometrial thickness was observed in atypical hyperplasia and carcinoma endometrium and lowest endometrial thickness in those with atrophic endometrium. A receiver operating characteristic (ROC) curve was plotted with the endometrial thickness by TVS as a variable against the occurrence of atypical hyperplasia and adenocarcinoma to identify the positive 
predictive value, negative predictive value, sensitivity and specificity (Table 1).

\section{Table 1: Correlation between EMT by TVS and histopathology.}

\begin{tabular}{|lll|}
\hline $\begin{array}{l}\text { Histopathology } \\
\text { of endometrium }\end{array}$ & $\begin{array}{l}\text { Endometrial } \\
\text { Thickness }(\mathrm{mm})\end{array}$ & $\begin{array}{l}\text { Mean } \pm \text { SD } \\
(\mathrm{mm})\end{array}$ \\
\hline Simple hyperplasia & $11-15$ & $13.33 \pm 1.63$ \\
\hline $\begin{array}{l}\text { Secretory } \\
\text { endometrium }\end{array}$ & $9-14$ & $11.33 \pm 2.14$ \\
\hline $\begin{array}{l}\text { Proliferative } \\
\text { endometrium }\end{array}$ & $4.9-27$ & $13.47 \pm 5.14$ \\
\hline $\begin{array}{l}\text { Atrophic } \\
\text { endometrium }\end{array}$ & $2.5-8$ & $5.88 \pm 1.17$ \\
\hline Atypical hyperplasia & $7.5-22$ & $14.21 \pm 5.29$ \\
\hline $\begin{array}{l}\text { Carcinoma } \\
\text { endometrium }\end{array}$ & $12-18$ & $14.75 \pm 2.50$ \\
\hline
\end{tabular}

Table 2: The ROC curve analysis.

\begin{tabular}{|c|c|}
\hline Classification variable & CA \\
\hline Sample size & 99 \\
\hline Positive group ${ }^{a}$ & $13(13.13 \%)$ \\
\hline Negative group ${ }^{b}$ & $86(86.87 \%)$ \\
\hline Disease prevalence $(\%)$ & 7 \\
\hline Area under the ROC curve (AUC) & 0.788 \\
\hline Standard Error ${ }^{a}$ & 0.0517 \\
\hline $95 \%$ Confidence interval $^{\mathrm{b}}$ & 0.694 to 0.864 \\
\hline z statistic & 5.568 \\
\hline Significance level P (Area $=0.5)$ & $<0.0001$ \\
\hline Youden index $\mathbf{J}$ & 0.5510 \\
\hline Associated criterion & $>10.8$ \\
\hline Sensitivity & 92.31 \\
\hline Specificity & 62.79 \\
\hline
\end{tabular}

${ }^{\mathrm{a}} \mathrm{CA}=1,{ }^{\mathrm{b}} \mathrm{CA}=0 ;{ }^{\mathrm{a}}$ DeLong et al, ${ }^{\mathrm{b}}$ Binomial exact

Endometrial thickness of $10.8 \mathrm{~mm}$ by TVS as a cut off value to identify malignant endometrial pathology, from ROC had $92.3 \%$ sensitivity and $62.8 \%$ specificity. Moreover, the negative predictive value $(99.1 \%)$ whereas the positive predictive value was $15.7 \%$.

Table 3: Criterion values and coordinates of the ROC curve.

\begin{tabular}{|lllllllll|}
\hline Criterion & Sensitivity & $95 \%$ CI & Specificity & $95 \%$ CI & +LR & -LR & +PV & -PV \\
\hline$\geq 2.5$ & 100.00 & $75.3-100.0$ & 0.00 & $0.0-4.2$ & 1.00 & & 7.0 & \\
\hline$>7$ & 100.00 & $75.3-100.0$ & 41.86 & $31.3-53.0$ & 1.72 & 0.00 & 11.5 & 100.0 \\
\hline$>7.5$ & 92.31 & $64.0-99.8$ & 43.02 & $32.4-54.2$ & 1.62 & 0.18 & 10.9 & 98.7 \\
\hline$>10.8$ & 92.31 & $64.0-99.8$ & 62.79 & $51.7-73.0$ & 2.48 & 0.12 & 15.7 & 99.1 \\
\hline$>11$ & 76.92 & $46.2-95.0$ & 70.93 & $60.1-80.2$ & 2.65 & 0.33 & 16.6 & 97.6 \\
\hline$>12$ & 61.54 & $31.6-86.1$ & 76.74 & $66.4-85.2$ & 2.65 & 0.50 & 16.6 & 96.4 \\
\hline$>13$ & 53.85 & $25.1-80.8$ & 80.23 & $70.2-88.0$ & 2.72 & 0.58 & 17.0 & 95.8 \\
\hline$>14$ & 38.46 & $13.9-68.4$ & 87.21 & $78.3-93.4$ & 3.01 & 0.71 & 18.5 & 95.0 \\
\hline$>15$ & 30.77 & $9.1-61.4$ & 89.53 & $81.1-95.1$ & 2.94 & 0.77 & 18.1 & 94.5 \\
\hline$>16$ & 15.38 & $1.9-45.4$ & 89.53 & $81.1-95.1$ & 1.47 & 0.95 & 10.0 & 93.4 \\
\hline$>17.2$ & 15.38 & $1.9-45.4$ & 91.86 & $83.9-96.7$ & 1.89 & 0.92 & 12.5 & 93.5 \\
\hline$>18$ & 7.69 & $0.2-36.0$ & 94.19 & $87.0-98.1$ & 1.32 & 0.98 & 9.1 & 93.1 \\
\hline$>20$ & 0.00 & $0.0-24.7$ & 94.19 & $87.0-98.1$ & 0.00 & 1.06 & 0.0 & 92.6 \\
\hline$>32$ & 0.00 & $0.0-24.7$ & 100.00 & $95.8-100.0$ & & 1.00 & 93.0 \\
\hline
\end{tabular}

\section{DISCUSSION}

Exclusion of carcinoma endometrium as the cause of PMB is the primary aim of evaluation in PMB patients. Fractional curettage is an invasive procedure and requires anesthesia and inherent risks of it. TVS has been suggested as a screening modality in patients with PMB. Increased endometrial thickness increases the risks of having malignancy.

Mean age of the population studied was $56.87 \pm 8.03$ years, comparable to a previous study by Kaur et al. ${ }^{20}$ The most common cause for PMB was atrophic endometrium $(35.78 \%)$ followed by proliferative endometrium $(27.59 \%)$ similar to the previously reported study. $31.4 \%$ each had atrophic and proliferative endometrium. Adenocarcinoma occurred in $4.5 \%$ of patients with PMB comparable to $5.71 \%$ observed by Kaur et al. ${ }^{20}$

Mean endometrial thickness was maximal in carcinoma endometrium i.e. $14.75 \pm 2.50 \mathrm{~mm}$ followed by atypical hyperplasia $14.21 \pm 5.29 \mathrm{~mm}$. But Higher values $29.5 \pm 3.54 \mathrm{~mm}$ and $16.45 \pm 3.98 \mathrm{~mm}$ respectively were reported by Kaur et al. Proliferative endometrium and simple hyperplasia showed endometrial thickness of $13.47 \pm 5.14 \mathrm{~mm}$ and $13.33 \pm 4.63 \mathrm{~mm}$ respectively similar to the observations by Kaur et al. ${ }^{20}$ 
The receiver operating Characteristic curve (ROC) plotted using endometrial thickness against endometrial carcinoma and atypical hyperplasia. A cut off value of $10.8 \mathrm{~mm}$ was identified. This cutoff had a high negative predictive value $(99.1 \%)$ and low positive predictive value. sensitivity and specificity were $92.3 \%$ and $62.79 \%$ respectively. Previous report by Kaur et al showed a cut off value of $4 \mathrm{~mm}$ with a sensitivity and specificity $100 \%$ and $72.73 \%$ respectively. The positive predictive value was $87.5 \%$ and negative predictive value of $100 \%$. Bindman SR et al reported that the risk of endometrium carcinoma is $6.7 \%$ if the endometrium is more than 11 $\mathrm{mm}$ thick and is $0.002 \%$ if the endometrium is below 11 $\mathrm{mm} .^{21}$

\section{CONCLUSION}

The thickness of endometrium as assessed by Transvaginal ultrasound (TVS) may be helpful in identifying the cause of post-menopausal bleeding (PMB). As per the ROC analysis of this study the endometrial thickness of $10.8 \mathrm{~mm}$ has a high negative predictive value $(99.1 \%)$ for malignancy with moderate specificity (62.79\%) and high sensitivity (92.3\%).

\section{ACKNOWLEDGEMENTS}

Authors would like to thank Dr. Nirmala. C professor and head, Department of Obstetrics and Gynecology for the help rendered in completion of the study and biostatitian Dr Babu. K for helping with the statistical analysis.

Funding: No funding sources

Conflict of interest: None declared

Ethical approval: The study was approved by the Institutional Ethics Committee

\section{REFERENCES}

1. Gimpleson RT, Rappold OH. A comparative study between panoramic hysteroscopy with directed biopsies and dilatation and curettage. Am J Obstet Gynaecol. 1988;158(3):489-92.

2. Colditz GA, Harkinson SE, Hunter AJ. The use of estrogens and progestins and the risk of breast cancer in postmenopausal women. $\mathrm{N}$ Engl $\mathrm{J}$ Med. 1995;332:1589-93.

3. Nachtigall MJ, Smilen SW, Nachtigall RD. Incidence of breast cancer in a 22-year study of women receiving estrogen-progestin replacement therapy. Obstet Gynecol. 1992;80:827-30.

4. Hacker NF, Moore JG. Essentials of Obstetrics and Gynecology, $3^{\text {rd }}$ Ed. Philadelphia. WB Saunders; 1998:635.

5. Tindall VR. Abnormal and excessive uterine bleeding. In: Jeffcoate's Principles of Gynaecology $5^{\text {th }} \mathrm{Ed} ; 1986: 512-532$.

6. Grimes DA. Diagnostic dilatation and curettage: a reappraisal. Am J Obstet Gynecol. 1982;142:1-6.
7. Mackenzie IZ, Bibby JZ. Critical assessment of dilatation and curettage in 1029 women. 1978;2:566.

8. Stock R, Kanbour A. Prehysterectomy curettage. Obstet Gynecol. 1975;45:537-41.

9. ACOG committee opinion 440. The role of Transvaginal ultrasound in the evaluation of post menopausal bleeding. Obstet Gynecol. 2009;114:409 $-11$.

10. Karlsson B, Granberg S, Wikland M, Ylostalo P, Torvid K, Marsal $\mathrm{K}$ et al. Transvaginal ultrasonography of the endometrium in women with post-menopausal bleeding-a Nordic multicenter study. Am J Obstet Gyecol.1995;172(5):1488-94.

11. Granberg S, Karlsson B, Wikland M, Gull B. Transvaginal sonography of uterine and endometrial disorders: Sonography in Obstetrics and Gynaecology. In Fleisher AL, Manning FA, Jeanty P, Romeo R. Principles and Practice. eds $5^{\text {th }}$ Ed. Stanford Appleton and Lange.1996;851-868.

12. Goldstein SR, Nachtigall M, Snyder JR, Nachtigall L. Endometrial assessment by vaginal ultrasonography before endometrial sampling in patients with postmenopausal bleeding. Am J Obstet Gynecol. 1990;163:119-230.

13. Conoscenti G, Meir YJ, Fisher TL, Maeiron A, Natale R, D'Ottavio G et al. Endometrial assessment by transvaginal sonography and histological findings after dilatation and curettage in women with postmenopausal bleeding. Ultrasound Obstet and Gynecol. 1995;6(2):108-15.

14. Guner H, Tiras Karabacak O, Sarikaya, Erdem H, Yildism M. Endometrial assessment by vaginal ultrasonography might reduce endometrial sampling in patients with postmenopausal bleeding: A prospective study. Aust NZ J Obstet Gynaecol. 1996;36(2):175-78.

15. Ciatto S, Cecchini S, Gervasi SG, Landini A, Zappa M, Crovetti E. Association of endometrial thickness assessed at Transvaginal ultrasonography to endometrial cancer in postmenopausal women asymptomatic or with abnormal uterine bleeding. Radiol Med (Torino). 2002;104(5-6):437-42.

16. Gull B, Karlsson B, Milson I, Granberg S. Can ultrasound replace dilatation and curettage? A longitudinal evaluation of postmenopausal bleeding and transvaginal sonographic measurement of the endometrium as predictors of endometrial cancer. Am J Obstet Gynaecol. 2003;188(2):401-8.

17. Getpook C, Wattanakumtornkul S. Endometrial thickness screening in premenopausal women with abnormal uterine bleeding. J Obstet Gynaecol Res. 2006;32(6):588-92.

18. Ellenson LH, Pirog EC In Pathologcal Basis of disease. Robbins and Coltran. $8^{\text {th }}$ ed. Philadelphia, Saunders Publications; 2010:1030-1.

19. Tongsong T, Pongnarisorn C, Mahanuphap P. Use of vaginal sonographic measurements of endometrial thickness in the identification of abnormal endometrium in peri and postmenopausal bleeding. $\mathbf{J}$ Clin Ultrasound. 1994;22:479-482. 
20. Kaur H, Goyal L, Kaur P. To validate the use of trans vaginal sonography-a noninvasive tool as a screening method for patients with postmenopausal bleeding. Internet J Gynecol Obstet. 2012;16(2):1-5.

21. Smith-Bindman R, Weiss E, Feldstein V. How thick is too thick? When endometrial thickness should prompt biopsy in postmenopausal women without vaginal bleeding. Ultrasound Obstet Gynecol. 2004;24(5):558-65.

Cite this article as: Menon S, Sreekumari R. Role of Transvaginal Ultrasound in assessment of endometrial pathology in patients with postmenopausal bleeding Int J Reprod Contracept Obstet Gynecol 2017;6:1376-80. 